\title{
Serum concentration of ketamine and antinociceptive effects of ketamine and ketamine-lidocaine infusions in conscious dogs
}

Ubedullah Kaka ${ }^{1,2}$, Bullo Saifullah ${ }^{3}$, Adamu Abdul Abubakar ${ }^{1}$, Yong Meng Goh ${ }^{4,5}$, Sharida Fakurazi ${ }^{6,7}$, Asmatullah Kaka ${ }^{1,9}$, Atique Ahmed Behan ${ }^{8,9}$, Mahdi Ebrahimi ${ }^{4}$ and Hui Cheng Chen ${ }^{1 *}$

\begin{abstract}
Background: Central sensitization is a potential severe consequence of invasive surgical procedures. It results in postoperative and potentially chronic pain enhancement. It results in postoperative pain enhancement; clinically manifested as hyperalgesia and allodynia. N-methyl-D-aspartate (NMDA) receptor plays a crucial role in the mechanism of central sensitisation. Ketamine is most commonly used NMDA-antagonist in human and veterinary practice. However, the antinociceptive serum concentration of ketamine is not yet properly established in dogs. Six dogs were used in a crossover design, with one week washout period. Treatments consisted of: 1) $0.5 \mathrm{mg} / \mathrm{kg}$ ketamine followed by continuous rate infusion (CRI) of $30 \mu \mathrm{g} / \mathrm{kg} / \mathrm{min} ; 2) 0.5 \mathrm{mg} / \mathrm{kg}$ ketamine followed by CRI of $30 \mu \mathrm{g} / \mathrm{kg} / \mathrm{min}$ and lidocaine ( $2 \mathrm{mg} / \mathrm{kg}$ followed by CRI of $100 \mu \mathrm{g} / \mathrm{kg} / \mathrm{min}$ ); and 3) $0.5 \mathrm{mg} / \mathrm{kg}$ ketamine followed by CRI of $50 \mathrm{\mu g} / \mathrm{kg} / \mathrm{min}$. The infusion was administered up to $120 \mathrm{~min}$. Nociceptive thresholds and ketamine serum concentrations were measured before drug administration, and at 5, 10, 20,40,60,90, 120, 140 and 160 min after the start of infusion.

Results: Maximum concentration recorded was $435.34 \pm 26.18 \mathrm{ng} / \mathrm{mL}, 582.34 \pm 227.46 \mathrm{ng} / \mathrm{mL}$ and $733.77 \pm 133$. $6 \mathrm{ng} / \mathrm{mL}$ for K30, KL30 and K50, respectively. The concentration at 120 min was $250.87 \pm 39.87,221.73 \pm 91.03$ and $343.67 \pm 63.21 \mathrm{ng} / \mathrm{mL}$ at $120 \mathrm{~min}$ in $\mathrm{K} 30, \mathrm{KL} 30$ and $\mathrm{K} 50$, respectively. All the three infusion regimes maintained serum concentrations above $200 \mathrm{ng} / \mathrm{mL}$. The thresholds returned towards baseline values within 20 min, after cessation of infusion.

Conclusion: Serum concentration to produce mechanical antinociceptive effects in dogs is between 100 and $200 \mathrm{ng} / \mathrm{mL}$. All the three infusion regimes in this study provided antinociceptive effects throughout the infusions. In this study, we found that the serum concentration of ketamine to produce mechanical antinociceptive effects in dogs is above $200 \mathrm{ng} / \mathrm{mL}$. All three infusion regimes provided antinociceptive effects throughout the infusions without causing harmful effects. Further studies are recommended in a clinical setting.
\end{abstract}

Keywords: Ketamine, NMDA receptor, Nociceptive mechanical thresholds, Dog, Lidocaine

\footnotetext{
* Correspondence: chen@upm.edu.my

${ }^{1}$ Department of Veterinary Clinical Studies, Faculty of Veterinary Medicine,

Universiti Putra Malaysia, 43400 Serdang, Selangor, Malaysia

Full list of author information is available at the end of the article
}

(C) 2016 The Author(s). Open Access This article is distributed under the terms of the Creative Commons Attribution 4.0 International License (http://creativecommons.org/licenses/by/4.0/, which permits unrestricted use, distribution, and reproduction in any medium, provided you give appropriate credit to the original author(s) and the source, provide a link to the Creative Commons license, and indicate if changes were made. The Creative Commons Public Domain Dedication waiver (http://creativecommons.org/publicdomain/zero/1.0/) applies to the data made available in this article, unless otherwise stated. 


\section{Background}

The glutamate-activated N-methyl-D-aspartate (NMDA) receptor plays a crucial role in the development of central sensitization. Some of the characteristics associated with central sensitization are manifested clinically by a painful sensation from a non-painful stimulus (allodynia) and augmented pain sensation from previously painful stimuli (hyperalgesia) [1-5].

Association of the NMDA receptor with postoperative pain ushered a new chapter in the exploration of NMDA-antagonists for postoperative analgesia protocol. Ketamine is well established NMDA- antagonist. It is commonly used as an anaesthetic agent in children and animals. It is useful for its anti-nociceptive properties in acute pain, and can be used for chronic and neuropathic pain as well [4]. Ketamine has prevented hyperalgesia, improved analgesia [6-8] and decreased postoperative opioid consumption [8-10] in surgical patients.

The analgesic dose range of ketamine for use in dogs has not been properly established. As a consequence, analgesic benefits of ketamine are not yet fully recognized in dogs. The effective dose range of ketamine in human surgical patients has been established at a loading dose of $0.5 \mathrm{mg} / \mathrm{kg}$, followed by continuous rate infusion (CRI) of 2 to10 $\mu \mathrm{g} / \mathrm{kg} / \mathrm{min}[7,10-12]$. In the absence of appropriate analgesic dose range, the doses used in studies of dogs [13-15] have been taken from human studies $[16,17]$. This has resulted in reporting inconclusive results. Moreover, most of the studies were clinical. Consequently, the use of opioids pre and postoperatively in these studies might have masked the analgesic effects of ketamine. Apart from this, various scoring scales used in these studies have not been validated for reliability, specificity or linearity. Most importantly these scales were based on subjective assessment of behaviour [18, 19], which can be biased by inter-observer variability. Furthermore, none of these studies correlated effects with serum concentrations of ketamine.

So far, only one study reported plasma concentration versus antinociceptive actions in dogs [20]. In this study, ketamine was administered at $0.5 \mathrm{mg} / \mathrm{kg}$, followed by $10 \mu \mathrm{g} / \mathrm{kg} / \mathrm{min}$ for $59 \mathrm{~min}$ in dogs, antinociceptive effect was demonstrated only for the first four minutes, at which time the plasma concentration was $>100 \mathrm{ng} / \mathrm{mL}$. Plasma concentration of ketamine declined to $<100 \mathrm{ng} / \mathrm{mL}$ after 5 min [20]. Further analysis revealed that the plasma concentrations of ketamine at pseudo-steady state were five times lower than the expected concentrations to that in humans receiving the same CRI. They concluded that this dose was insufficient to maintain the analgesic concentration of the ketamine. This also suggests that ketamine pharmacokinetics in dogs may differ from that in humans, and that may warrant the use of higher infusion rates in dogs.
Lidocaine is commonly used as a local anaesthetic and anti-arrhythmic agent in veterinary and human medicine. With the mechanism based approach combination of lidocaine acting on sodium channels, which play a part in generation and transmission of nociceptive impulses [1] and ketamine acting on NMDA receptors would be better strategy to manage postoperative pain, compared to conventional method of administering single drug for post operative pain management. The major benefit of combining lidocaine and ketamine is to prevent the development of central sensitization during surgical intervention [21], which may reduce pain and discomfort in the postoperative period. The combination of ketamine and lidocaine has been reported to decrease the minimum alveolar concentration (MAC) of inhalant anaesthetics in dogs [22-25]. It has been suggested that the MAC reducing effect may be due to analgesic or sedative effect or both $[22,24,25]$. The analgesic effects of the combination of lidocaine and ketamine in conscious dogs have not been reported.

This study therefore, aimed to correlate the serum concentrations of ketamine to the antinociceptive effects using two infusion rates of ketamine. Furthermore, this study also evaluated the clinical and antinociceptive effects of incorporation of lidocaine infusion to ketamine in a controlled, repeatable situation.

\section{Methods}

\section{Animals and treatments}

Six adult healthy mix-breed female dogs weighing $17.2 \pm$ $2.2 \mathrm{~kg}($ Mean $\pm \mathrm{SD})$ with the age of 2 to 10 years old were used in this study. Animals were obtained from a local stray animal holding facility following informed consent. These animals were acclimatized for one month, during this period they were kept under observation for any disease or abnormality. Dogs were judged healthy based on physical examination, hematology, and blood biochemistry, and have not been showing any sign of illness during one month of previous observation. Animals were brought daily to the experimental room, which was adjacent to the kennels, in order to familiarise them with the experimental station. Experiments were conducted in animal experimental station in a quiet environment with minimum number of observers. Experiments were conducted in day time, starting at 8:00 am. The study was approved by the Universiti Putra Malaysia Animal Care and Utility Committee (Reference Number UPM/IACUC/ AUP-R023/2013).

All six dogs were subjected to three treatment protocols in a randomized crossover design with one-week washout period between the treatments. Treatment protocols were: 1) $0.5 \mathrm{mg} / \mathrm{kg}$ ketamine (NARKETAN ${ }^{\circ}-10$, $100 \mathrm{mg} / \mathrm{mL}$, Vetoquinol UK Limited, Buckingham, UK) followed by continuous rate infusion (CRI) of $30 \mu \mathrm{g} / \mathrm{kg} /$ 
min (K30); 2) Combination of ketamine (0.5 mg/kg followed by CRI of $30 \mu \mathrm{g} / \mathrm{kg} / \mathrm{min}$ ) and lidocaine hydrochloride (Xylocaine $2 \%$ AstraZeneca, France) $2 \mathrm{mg} / \mathrm{kg}$ followed by CRI of $100 \mu \mathrm{g} / \mathrm{kg} / \mathrm{min}$ (KL30); and 3) $0.5 \mathrm{mg} /$ $\mathrm{kg}$ ketamine followed by CRI of $50 \mu \mathrm{g} / \mathrm{kg} / \mathrm{min}$ (K50).

The loading doses of K30, KL30 and K50 were mixed in normal saline to a final volume of $3 \mathrm{~mL}$ and injected over one minute. Ketamine was diluted with normal saline to $5 \mathrm{mg} / \mathrm{mL}$ and lidocaine $16.66 \mathrm{mg} / \mathrm{mL}$ for infusion. Infusions were delivered for $120 \mathrm{~min}$ through a precision syringe pump (Omnifuse, Graseby medical limited, United Kingdom). Right and left cephalic veins were catheterized with $20 \mathrm{G}$ indwelling catheters (Vasofix ${ }^{\circledR}$ Braunule $^{\ominus}$, B. Braune Melsungen AG 34209 Melsungen, Germany) for blood sampling and infusion of drugs, respectively. Prior to the actual study, the infusion regimens were tested in two of the six dogs.

\section{Algometer device}

Wagner algometer (FPX 25, Wagner Instruments, Greenwich CT, USA) with a modified tip was used in this study.

\section{Nociceptive mechanical thresholds}

The nociceptive mechanical thresholds were recorded in duplicates from the carpal pad, metacarpal footpad, tibia and femur of right limbs, and the abdomen. Thresholds were determined before treatment as baseline and then after start of treatment at 10, 20, 40, 60, 90, 120, 140 and $160 \mathrm{~min}$. These body points were selected based on models used in the previous studies [26-28] conducted in dogs. The carpal pad and metacarpal pad were tested by applying the tip of the algometer at midpoint of these pads. The tibia was tested on the distal latero-dorsal surface where bone could be palpated through the skin. The femur was tested on the distal latero-dorsal surface, where the bone could be palpated through the skin by displacing the muscle with little pressure applied with fingers. The abdomen was tested on the midline at the midpoint between umbilicus and pubis. The order of testing was firstly the metacarpal pad, followed by carpal pad, femur, tibia, and finally, the abdomen. At each testing point, the tip was placed perpendicular to the surface area. The pressure was increased gradually until the dog responded. The entire threshold recording was performed by the same researcher. During thresholds determination, the operator did not look at the reading of the algometer as he applied consistent force. Instead, he concentrated on the dogs' response and immediately stopped at response. The end-points were cross-checked by another observer who took note of both the algometer readings and dogs' response. The most common response identified during the preliminary trial was clear withdrawal reflex of the limb, vocalization, withdrawal of the limb accompanied with vocalization and guarding of the abdomen. According to Le Bars et al. (2001), in order to avoid tissue damage, cut-off pressure should be set at three times the thresholds of control [29]. Preliminary trials and the baseline thresholds on body points tested in this study were 5 to 6 Newtons $(\mathrm{N})$. Thus, the cut-off pressure was set at $18 \mathrm{~N}$ for this study. If no reaction was perceived before the cut-off limit, this value $(18 \mathrm{~N})$ was recorded as the mechanical nociceptive threshold. One of the dogs did not respond to application of the algometer up to the cut-off point of $18 \mathrm{~N}$ at its abdomen, thus, was not tested at abdomen for all treatment groups.

\section{Sedation score and side effects}

A composite sedation score and a behavioural chart adopted from Bergadano et al. (2009) were used to evaluate the psychomimetic side effects of ketamine at the measurement time points [20]. The sedation score on a 0 (no sedation) to 12 (deep sedation) scale, was assigned by adding the ranking of different descriptors (Table 1). The incidence of psychomimetic signs (disorientation, lateral head movements, fixed eyes, apneustic respiration, salivation, tremors and hyperactivity) was noted for each treatment group. The person involved in scoring sedation and side effects was blinded to the treatments.

\section{Blood sampling}

Blood samples were taken before administration of treatment as baseline, and then at 1, 5, 10, 20, 40, 60, 90, 120 and $140 \mathrm{~min}$ after the start of infusion. At each time points, $2 \mathrm{~mL}$ of blood was sampled and kept in plain sampling tubes (BD Vacutainer ${ }^{\oplus}$, BD Franklin Lakes NJ USA), and immediately placed on ice. Samples were centrifuged and serum was harvested, and then frozen at $-80{ }^{\circ} \mathrm{C}$ until analysis.

Table 1 Sedation score scale used in this system (Adopted from Bergadano et al. 2009)

\begin{tabular}{llll}
\hline Score & Consciousness & Eye & Responsiveness \\
\hline 0 & Awake & Not rotated & Respond to voice \\
1 & Aware & Moderate rotation & Respond to gentle touch \\
2 & Not aware but arousable & Rotated & Does not respond to touch \\
3 & Not aware and not arousable & Nystagmus & Hyperexcitable \\
\hline
\end{tabular}


High performance liquid chromatography analysis

Ketamine concentration in serum was determined using high performance liquid chromatography (HPLC). In brief, the system consisted of Waters HPLC 2695 separation module, an Agilent C18 column (5 $\mu \mathrm{m}$ particle size; $4.6 \times 150 \mathrm{~mm}$ ), photodiode array (PDA) detector and a computer equipped with Empower software (Waters, Milford, MA, USA).

\section{Extraction of drug from serum}

The ketamine was extracted from serum by the method reported earlier (Doherty et al. 2007). Briefly, the frozen serum samples were thawed followed by vortex mixing and transferred to $1 \mathrm{~mL}$ of glass test tube containing $25 \mu \mathrm{L}$ of (internal standard, $50 \mu \mathrm{g} / \mathrm{mL}$ ) trimethoprim. Further, $200 \mu \mathrm{L}$ of 1 molar solution $(1 \mathrm{M})$ of sodium hydroxide $(\mathrm{NaOH})$ and $5 \mathrm{~mL}$ methylene chloride $\left(\mathrm{CH}_{2} \mathrm{Cl}_{2}\right)$ were added to above samples. Tubes were vortex mixed again and then centrifuged for $20 \mathrm{~min}$ at $1500 \mathrm{~g}$. The organic layer was separated and placed in clean tube evaporated with gentle stream of nitrogen till dryness. Finally, samples were reconstituted with $1 \mathrm{~mL}$ of mobile phase and $100 \mu \mathrm{L}$ was injected for HPLC analysis.

\section{Sample analysis}

In brief, freshly prepared isocratic mixture of $0.02 \mathrm{M}$ potassium dihydrogen phosphate $\left(\mathrm{KH}_{2} \mathrm{PO}_{4}\right) \mathrm{pH} 4.5$, adjusted with phosphoric acid and acetonitrile (ACN) (ACN: $\mathrm{KH}_{2} \mathrm{PO}_{4}(40: 60)$ was used as mobile phase with flow rate of $1.0 \mathrm{~mL} / \mathrm{min}$. Calibration curves for serum analysis were prepared by spiking the dog serum with ketamine. A linear concentration range of 25-1500 ng/mL was established with $\mathrm{r}^{2}$ value of 0.99 .

\section{Statistical analysis}

Data are presented as mean \pm standard deviation. Statistical analysis was performed using the SAS software package, version 9.3 (SAS Institute Inc., Cary, NC, USA). Prior to the analysis, data were checked for their conformance to the normal distribution using KolmogrovSimirnov test. Changes in mechanical thresholds and serum concentrations over time and across treatment groups were compared using the repeated-measures ANOVA model. Bonferroni adjusted $P$ values were used when indicated by a significant $F$ test $(P<0.05)$. Correlation between the mechanical thresholds and serum concentrations of ketamine was calculated with Pearson test. Effects of treatment over time on sedation score were analyzed using Friedman's test. Overall significance was set at a value of $P<0.05$. The observed power for the current study was determined to be $80.53 \%$ for 1-Way ANOVA, and $90.75 \%$ for Repeated Measure ANOVA. This was based on an effect size value of 0.8165 , obtained by calculating the serum ketamine concentrations $1 \mathrm{~min}$ after administration (peak value), and at $120 \mathrm{~min}$ after administration. Power calculations were performed using G*Power Software, version 3.1.9.2 [30].

\section{Results}

The experiments were well tolerated by all the dogs. Changes in behavior due to recognized psychomimetic effects of ketamine were mild and harmless. The behavioral changes disappeared within $20 \mathrm{~min}$ after the end of infusion, and the dogs resumed their activity immediately after the end of experiment. The algometer device was well tolerated by all the animals. Transient dimples were observed at the carpal pad, metacarpal footpad, and abdomen, which disappeared within $1 \mathrm{~min}$, before the replicate measurement. There was no sign of redness, swelling, bleeding, exudates, and lameness during, immediately after, and $24 \mathrm{~h}$ after the experiment.

\section{Serum concentrations of ketamine}

The serum concentrations (Mean \pm SD) of K30, KL30 and $\mathrm{K} 50$ across time points are illustrated in Fig. 1. Maximum concentration was observed at $1 \mathrm{~min}$ for K30 $(435.34 \pm 26.18 \mathrm{ng} / \mathrm{mL}), \mathrm{KL} 30(582.34 \pm 227.46 \mathrm{ng} / \mathrm{mL})$, and $\mathrm{K} 50(733.77 \pm 133.6 \mathrm{ng} / \mathrm{mL})$, which remained stable for $20 \mathrm{~min}$, and declined gradually reaching around $250.87 \pm 39.87,221.73 \pm 91.03$ and $343.67 \pm 63.21 \mathrm{ng} / \mathrm{mL}$ at $120^{\text {th }} \mathrm{min}$ in K30, KL30 and K50, respectively. The serum concentration decreased rapidly to less than $100 \mathrm{ng} / \mathrm{mL}$ within $20 \mathrm{~min}$ following the end of infusions in all three treatments. Between 1 and $40 \mathrm{~min}$, serum concentration of $\mathrm{K} 50$ was higher than $\mathrm{K} 30$, while concentration of KL30 lied in between $\mathrm{K} 50$ and K30. By $60^{\text {th }} \mathrm{min}$, the three groups were not statistically different.

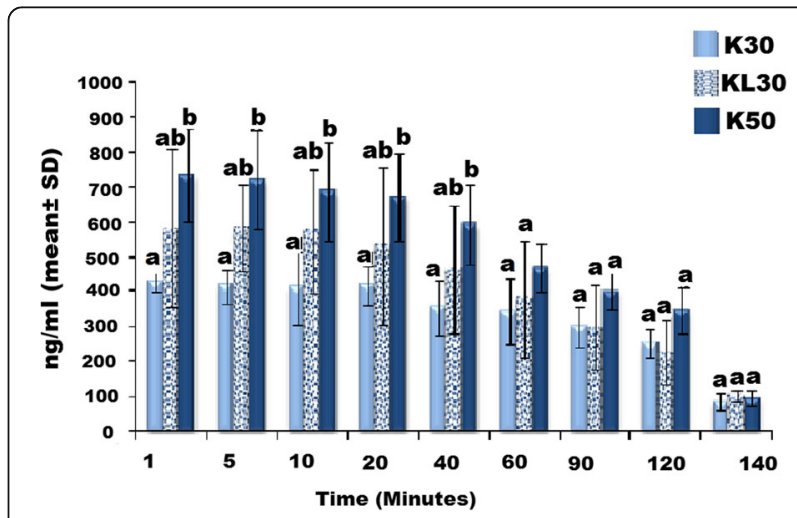

Fig. 1 Comparison (Mean \pm SD) between serum concentration of K30, $\mathrm{KL} 30$ and $\mathrm{K} 50$ in 6 dogs during and after CRI. K30 = Ketamine $0.5 \mathrm{mg} /$ $\mathrm{kg}$ loading dose followed by $30 \mu \mathrm{g} / \mathrm{kg} / \mathrm{min}, \mathrm{KL} 30=$ Ketamine $0.5 \mathrm{mg} /$ $\mathrm{kg}$ loading dose followed by $30 \mathrm{\mu g} / \mathrm{kg} / \mathrm{min}$ and lidocaine $2 \mathrm{mg} / \mathrm{kg}$ loading dose followed by $100 \mu \mathrm{g} / \mathrm{kg} / \mathrm{min}, \mathrm{K} 50$ = Ketamine $0.5 \mathrm{mg} / \mathrm{kg}$ loading dose followed by $50 \mu \mathrm{g} / \mathrm{kg} / \mathrm{min}$ CRl. At each time point, groups with similar alphabet are not different $(P<0.05)$ 
Nociceptive mechanical thresholds

There was no significant difference among the baseline mechanical thresholds at carpal pad, metacarpal foot pad, tibia, femur and abdomen in all treatment groups (Fig. 2a-e). All the three treatments increased thresholds significantly $(P<0.05)$ throughout the infusion up to $120 \mathrm{~min}$. Mechanical thresholds returned to baseline within $20 \mathrm{~min}$ of the end of CRI at $140^{\text {th }} \mathrm{min}$. Overall, nociceptive mechanical thresholds were higher in KL30 than in $\mathrm{K} 30$ and also higher in $\mathrm{K} 50$ than in KL30, and some significant differences between groups were recorded. There was weak positive correlation between serum concentration of $\mathrm{K} 30$ with mechanical thresholds at carpal pad $(\mathrm{r}-0.24 P=0.141)$, metacarpal footpad $(\mathrm{r}-0.32, P=0.053)$, tibia $(\mathrm{r}-0.33, P=0.047)$, femur $(\mathrm{r}-0.30, P=0.075)$ and abdomen $(\mathrm{r}-0.35, P=0.053)$. Likewise, weak positive correlation of $\mathrm{K} 50$ with mechanical thresholds at carpal pad $(\mathrm{r}-0.29 P=0.080)$, metacarpal footpad ( $\mathrm{r}-0.38, P=0.020)$, tibia $(\mathrm{r}-0.18, P=0.330)$, femur (r-0.22, $P=0.185)$ and abdomen $(\mathrm{r}-0.12, P=0.527)$ were observed.

\section{Heart rate, body temperature and respiration}

Baseline heart rates were not different amongst all treatments. Heart rates increased significantly from baselines in all treatments during the $120 \mathrm{~min}$ of treatment infusions. Following cessation of infusions, heart rates decreased, but remained higher than baselines in KL30 and K50. Heart rates between K30 and KL30 were not different, while $\mathrm{K} 50$ resulted in higher heart rates compared to $\mathrm{K} 30$ at 40 to $60 \mathrm{~min}$ and KL30 at 40 to $120 \mathrm{~min}$ (Table 2). Body temperatures increased significantly from baselines throughout the 160-minute study period in $\mathrm{K} 30$ and KL30 groups, and up to $120 \mathrm{~min}$ in K50 (Table 3). This increase in body temperature was within the normal range. The change in respiration was insignificant in K30, while KL30 and K50 resulted in increased respiratory rates at 120 to 160 , and 20 to $160 \mathrm{~min}$, respectively.
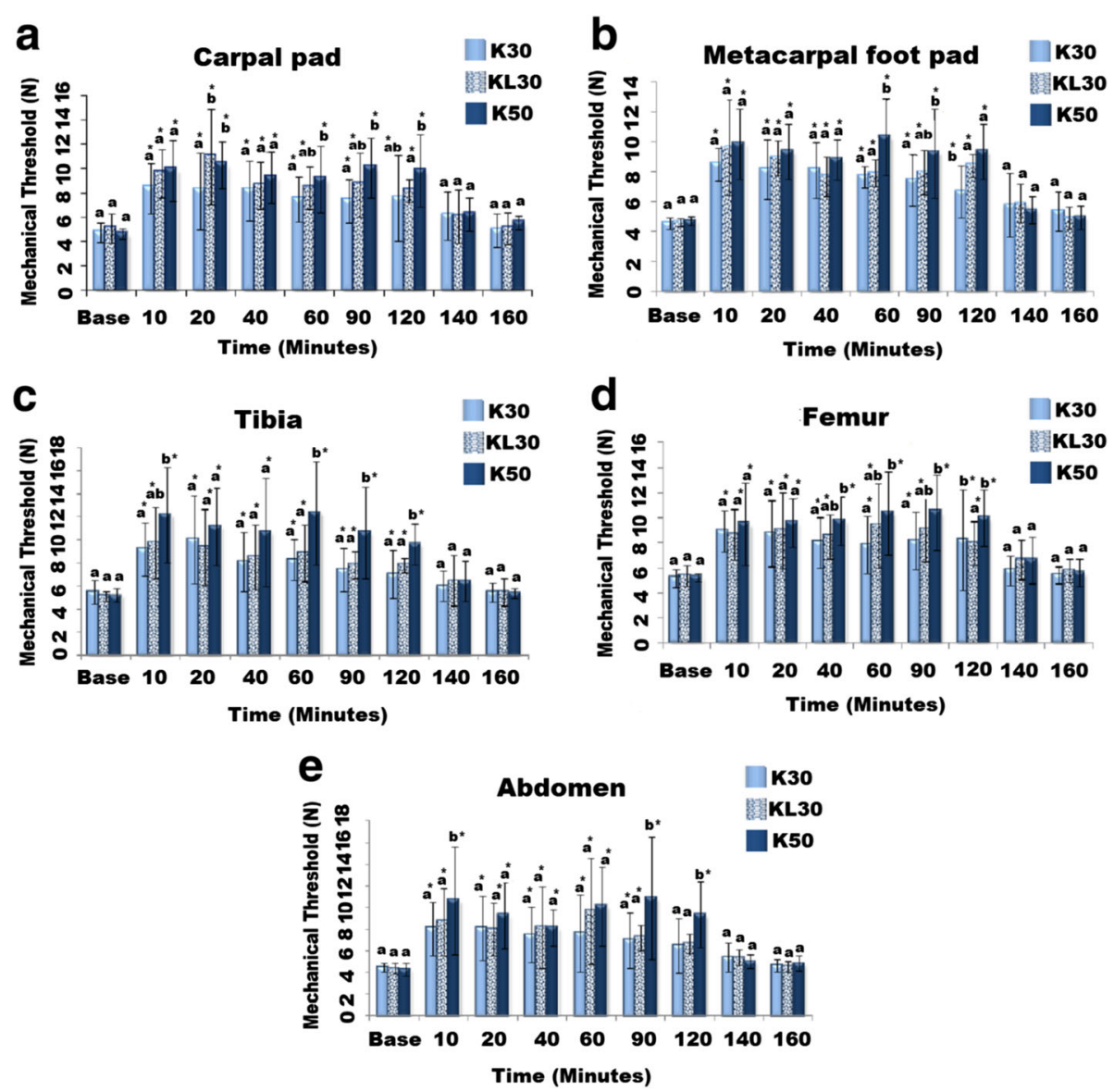

Fig. 2 Effects of K30, KL30 and K50 on mechanical nociceptive thresholds measured at the carpal pad (a), metacarpal footpad (b), tibia (c), femur (d) $(n=6)$ and abdomen (e) $(n=5)$. K30 = Ketamine $0.5 \mathrm{mg} / \mathrm{kg}$ loading dose followed by $30 \mu \mathrm{g} / \mathrm{kg} / \mathrm{min} \mathrm{CRl,} \mathrm{KL30=Ketamine} 0.5 \mathrm{mg} / \mathrm{kg}$ loading dose followed by $30 \mu \mathrm{g} / \mathrm{kg} / \mathrm{min}$ and lidocaine hydrochloride $2 \mathrm{mg} / \mathrm{kg}$ loading dose followed by $100 \mu \mathrm{g} / \mathrm{kg} / \mathrm{min}$ CRI, K50=Ketamine $0.5 \mathrm{mg} / \mathrm{kg}$ loading dose followed by $50 \mathrm{\mu g} / \mathrm{kg} / \mathrm{min} \mathrm{CRI}$. Data are expressed as mean \pm SD. * denotes significant difference from baseline within treatment, at each time point, groups with similar alphabet are not different $(P<0.05)$ 
Table 2 Effects of K30, KL30 and K50 on heart rates (Mean \pm SD) measured in 6 dogs using crossover design

\begin{tabular}{|c|c|c|c|}
\hline & K30 & KL30 & K50 \\
\hline Baseline & $79 \pm 6$ & $77 \pm 7$ & $81 \pm 6$ \\
\hline $20 \mathrm{~min}$ & $113 \pm 24^{a}$ & $101 \pm 19^{a}$ & $113 \pm 22^{a}$ \\
\hline $40 \mathrm{~min}$ & $104 \pm 16^{\mathrm{a}}$ & $99 \pm 18^{a}$ & $123 \pm 19^{a b c}$ \\
\hline $60 \mathrm{~min}$ & $105 \pm 15^{a}$ & $104 \pm 260^{a}$ & $124 \pm 23^{\mathrm{abc}}$ \\
\hline $90 \mathrm{~min}$ & $113 \pm 15^{\mathrm{a}}$ & $107 \pm 21^{\mathrm{a}}$ & $127 \pm 25^{\mathrm{ac}}$ \\
\hline $120 \mathrm{~min}$ & $106 \pm 19^{a}$ & $98 \pm 20^{a}$ & $114 \pm 14^{\mathrm{ac}}$ \\
\hline $140 \mathrm{~min}$ & $93 \pm 20$ & $93 \pm 12^{a}$ & $99 \pm 15^{a}$ \\
\hline $160 \mathrm{~min}$ & $86 \pm 14$ & $94 \pm 11^{a}$ & $102 \pm 25^{a b}$ \\
\hline \multicolumn{4}{|c|}{ 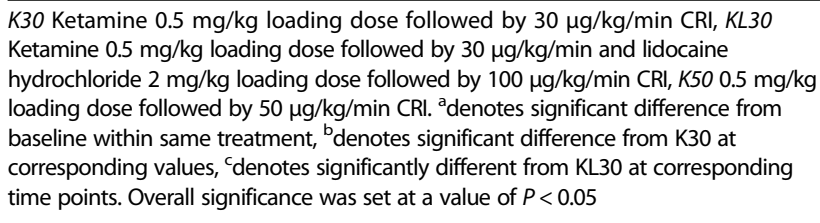 } \\
\hline
\end{tabular}

Respiratory rate increased from $33 \pm 7$ at baseline, to as much as $93 \pm 5$ breaths per minute in KL30, and from $29 \pm$ 7 at baseline, to as much as $93 \pm 5$ breaths per minute in K50 during infusion of treatment.

\section{Sedation and side effects}

Sedation score and side effects are presented in Tables 4 and 5. There was significant difference in the sedation score between K30, KL30 and K50 groups. The median sedation scores were 0 throughout the 160-minute study period in $\mathrm{K} 30$ and KL30. In contrast, median score in K50 were 3 between 1 and $20 \mathrm{~min}$, and reduced to 1 between 40 and $90 \mathrm{~min}$. Most of the dogs exhibited one or more side effects such as disorientation, swaying of the head, salivation and hyperactivity. These effects were observed throughout the duration of $120 \mathrm{~min}$ infusion and disappeared at $140^{\text {th }}$ min, which is within $20 \mathrm{~min}$ after

Table 3 Effects of K30, KL30 and K50 on body temperatures (Mean $\pm \mathrm{SD}$ ) measured in 6 dogs using crossover design

\begin{tabular}{llll}
\hline & K30 & KL30 & K50 \\
\hline Baseline & $38.6 \pm 0.4$ & $38.7 \pm 0.3$ & $38.8 \pm 0.2$ \\
$20 \mathrm{~min}$ & $39.0 \pm 0.5^{\mathrm{a}}$ & $39.1 \pm 0.6^{\mathrm{a}}$ & $39.2 \pm 0.6^{\mathrm{a}}$ \\
$40 \mathrm{~min}$ & $39.1 \pm 0.6^{\mathrm{a}}$ & $39.0 \pm 0.5^{\mathrm{a}}$ & $39.3 \pm 0.5^{\mathrm{a}}$ \\
$60 \mathrm{~min}$ & $39.2 \pm 0.4^{\mathrm{a}}$ & $39.1 \pm 0.4^{\mathrm{a}}$ & $39.3 \pm 0.5^{\mathrm{a}}$ \\
$90 \mathrm{~min}$ & $39.2 \pm 0.4^{\mathrm{a}}$ & $39.1 \pm 0.4^{\mathrm{a}}$ & $39.0 \pm 0.4^{\mathrm{a}}$ \\
$120 \mathrm{~min}$ & $39.1 \pm 0.5^{\mathrm{a}}$ & $39.1 \pm 0.5^{\mathrm{a}}$ & $39.0 \pm 0.3^{\mathrm{a}}$ \\
$140 \mathrm{~min}$ & $39.3 \pm 0.5^{\mathrm{a}}$ & $39.2 \pm 0.4^{\mathrm{a}}$ & $39.0 \pm 0.3$ \\
$160 \mathrm{~min}$ & $39.0 \pm 0.4^{\mathrm{a}}$ & $39.1 \pm 0.5^{\mathrm{a}}$ & $39.0 \pm 0.3$ \\
\hline
\end{tabular}

K30 Ketamine $0.5 \mathrm{mg} / \mathrm{kg}$ loading dose followed by $30 \mu \mathrm{g} / \mathrm{kg} / \mathrm{min}$ CRI, KL30 Ketamine $0.5 \mathrm{mg} / \mathrm{kg}$ loading dose followed by $30 \mu \mathrm{g} / \mathrm{kg} / \mathrm{min}$ and lidocaine hydrochloride $2 \mathrm{mg} / \mathrm{kg}$ loading dose followed by $100 \mu \mathrm{g} / \mathrm{kg} / \mathrm{min}$ CRI, K50 $0.5 \mathrm{mg} / \mathrm{kg}$ loading dose followed by $50 \mu \mathrm{g} / \mathrm{kg} / \mathrm{min}$ CRI a denotes significant difference from baseline within same treatment. Overall significance was set at a value of $P<0.05$
Table 4 Sedation score in median (IQR) values across each time points of the each group after administration of $\mathrm{K} 30, \mathrm{~K} 50$, and $\mathrm{KL} 30$ in 6 dogs

\begin{tabular}{llll}
\hline Time (minutes) & $\mathrm{K} 30$ & $\mathrm{KL} 30$ & $\mathrm{~K} 50^{\mathrm{a}}$ \\
\hline 0 & $0(0-0)$ & $0(0-0)$ & $0(0-0)$ \\
01 & $0(0-0)$ & $0(0-0)$ & $3(0-3)$ \\
05 & $0(0-0)$ & $0(0-0)$ & $3(0-3)$ \\
20 & $0(0-0)$ & $0(0-0)$ & $3(0-3)$ \\
40 & $0(0-0)$ & $0(0-0)$ & $1(0-3)$ \\
60 & $0(0-0)$ & $0(0-0)$ & $1(0-3)$ \\
90 & $0(0-0)$ & $0(0-0)$ & $1(0-3)$ \\
120 & $0(0-0)$ & $0(0-0)$ & $0(0-0)$ \\
140 & $0(0-0)$ & $0(0-0)$ & $0(0-0)$ \\
160 & $0(0-0)$ & $0(0-0)$ & $0(0-0)$ \\
\hline
\end{tabular}

K30 ketamine $0.5 \mathrm{mg} / \mathrm{kg}$ loading dose followed by $30 \mu \mathrm{g} / \mathrm{kg} / \mathrm{min}, K 500.5 \mathrm{mg} / \mathrm{kg}$ loading dose followed by $50 \mu \mathrm{g} / \mathrm{kg} / \mathrm{min}, K L=$ ketamine 0.5 loading dose followed by $30 \mu \mathrm{g} / \mathrm{kg} / \mathrm{min}$ + lidocaine $2 \mathrm{mg} / \mathrm{kg}$ loading dose followed by $100 \mu \mathrm{g} / \mathrm{kg} / \mathrm{min}$. Overall significance was set at a value of $P<0.05$. ${ }^{\text {a }} \mathrm{K} 50$ is significantly different from K30 and KL at $P<0.003$ (Friedman test)

the end of infusions. The side effects were less severe in K30 and KL30 compared to K50.

\section{Discussion}

The concentrations of ketamine in the present study were $435.34 \pm 26.18 \mathrm{ng} / \mathrm{mL}$ for $\mathrm{K} 30,582.34 \pm 227.46 \mathrm{ng} / \mathrm{mL}$ for KL30 and $733.77 \pm 133.6 \mathrm{ng} / \mathrm{mL}$ for $\mathrm{K} 50$ at $1 \mathrm{~min}$ and $250.87 \pm 39.87,221.73 \pm 91.03$ and $343.67 \pm 63.21 \mathrm{ng} / \mathrm{mL}$ at $120 \mathrm{~min}$ for K30, KL30 and K50, respectively. The serum concentrations of ketamine produced by all the 3 CRI regimens in this study could be maintained above $100 \mathrm{ng} / \mathrm{mL}$ during the 120- min infusions. Furthermore, nociceptive thresholds at most body points were raised above baseline values during the $120 \mathrm{~min}$ of infusions. The nociceptive thresholds returned towards baseline values within 20 min after cessation of infusions, at which point, serum levels were found to be lower than $100 \mathrm{ng} /$ $\mathrm{mL}$. Results from this study suggested that the minimum concentration of ketamine to produce analgesia in dogs is between 100 as observed at $140 \mathrm{~min}$ and $200 \mathrm{ng} / \mathrm{mL}$ during infusion. This concurred with findings in humans, where serum concentration of $100-200 \mathrm{ng} / \mathrm{mL}$ of ketamine was reported to be analgesic with minimal side effects $[11,31]$.

Effective analgesic concentration of ketamine has not been reported in dogs. The only study reporting the analgesic concentration of ketamine versus its antinociceptive action in dogs has been conducted by Bergadano et al. [20]. They found that the analgesic effect only lasted for the first four minutes at plasma concentration of 220-370 ng/ mL. No further analgesic effect was observed thereafter for up to $59 \mathrm{~min}$, when plasma concentration was found to be below $100 \mathrm{ng} / \mathrm{mL}$. They selected 
Table 5 Frequency of side effects (number of dogs out of six showing a specific psychomimetic sign)

\begin{tabular}{|c|c|c|c|c|c|c|c|c|c|c|c|}
\hline & & $0 \mathrm{~min}$ & $1 \mathrm{~min}$ & $5 \mathrm{~min}$ & $20 \mathrm{~min}$ & $40 \mathrm{~min}$ & $60 \mathrm{~min}$ & $90 \mathrm{~min}$ & $120 \mathrm{~min}$ & $140 \mathrm{~min}$ & $160 \mathrm{~min}$ \\
\hline \multirow[t]{3}{*}{ Disorientation/confused } & K30 & 0 & 5 & 5 & 4 & 3 & 3 & 3 & 3 & 0 & 0 \\
\hline & K50 & 0 & 5 & 5 & 6 & 6 & 6 & 5 & 6 & 0 & 0 \\
\hline & KL30 & 0 & 4 & 5 & 5 & 5 & 5 & 5 & 5 & 0 & 0 \\
\hline \multirow[t]{3}{*}{ Lateral head movements } & K30 & 0 & 3 & 3 & 2 & 2 & 2 & 2 & 2 & 0 & 0 \\
\hline & K50 & 0 & 5 & 5 & 6 & 6 & 6 & 5 & 5 & 0 & 0 \\
\hline & KL30 & 0 & 3 & 4 & 4 & 4 & 4 & 4 & 4 & 0 & 0 \\
\hline \multirow[t]{3}{*}{ Glazy Eyes } & K30 & 0 & 0 & 0 & 0 & 0 & 0 & 0 & 0 & 0 & 0 \\
\hline & K50 & 0 & 0 & 0 & 0 & 0 & 0 & 0 & 0 & 0 & 0 \\
\hline & KL30 & 0 & 0 & 0 & 0 & 0 & 0 & 0 & 0 & 0 & 0 \\
\hline \multirow[t]{3}{*}{ Apneustic respiration } & K30 & 0 & 0 & 0 & 0 & 0 & 0 & 0 & 0 & 0 & 0 \\
\hline & K50 & 0 & 0 & 0 & 0 & 0 & 0 & 0 & 0 & 0 & 0 \\
\hline & KL30 & 0 & 0 & 0 & 0 & 0 & 0 & 0 & 0 & 0 & 0 \\
\hline \multirow[t]{3}{*}{ Salivation } & K30 & 0 & 4 & 4 & 4 & 4 & 4 & 4 & 4 & 0 & 0 \\
\hline & K50 & 0 & 4 & 4 & 4 & 4 & 4 & 4 & 4 & 0 & 0 \\
\hline & KL30 & 0 & 4 & 4 & 4 & 4 & 4 & 4 & 4 & 4 & 0 \\
\hline \multirow[t]{3}{*}{ Tremors } & K30 & 0 & 0 & 0 & 0 & 0 & 0 & 0 & 0 & 0 & 0 \\
\hline & K50 & 0 & 0 & 0 & 0 & 0 & 0 & 0 & 0 & 0 & 0 \\
\hline & KL30 & 0 & 0 & 0 & 0 & 0 & 0 & 0 & 0 & 0 & 0 \\
\hline \multirow[t]{3}{*}{ Hyperactivity } & K30 & 0 & 1 & 1 & 1 & 1 & 1 & 1 & 1 & 0 & 0 \\
\hline & K50 & 0 & 3 & 3 & 3 & 3 & 3 & 3 & 3 & 0 & 0 \\
\hline & KL30 & 0 & 2 & 2 & 2 & 1 & 1 & 0 & 0 & 0 & 0 \\
\hline
\end{tabular}

K30 ketamine $0.5 \mathrm{mg} / \mathrm{kg}$ loading dose followed by $30 \mu \mathrm{g} / \mathrm{kg} / \mathrm{min}, \mathrm{K} 500.5 \mathrm{mg} / \mathrm{kg}$ loading dose followed by $50 \mu \mathrm{g} / \mathrm{kg} / \mathrm{min}$, KL30 ketamine 0.5 loading dose followed by $30 \mu \mathrm{g} / \mathrm{kg} / \mathrm{min}$ + lidocaine $2 \mathrm{mg} / \mathrm{kg}$ loading dose followed by $100 \mu \mathrm{g} / \mathrm{kg} / \mathrm{min}$

a ketamine dose of $0.5 \mathrm{mg} / \mathrm{kg}$ and $10 \mu \mathrm{g} / \mathrm{kg} / \mathrm{min}$ from the human studies $[16,17,31,32]$. However, these dosages had difficulties to sustain a desired plasma ketamine concentration (i.e. above $100-200 \mathrm{ng} / \mathrm{mL}$ ) to produce antinociceptive effect conscious dogs. The authors suggested that this variation was due the difference in pharmacokinetics of ketamine between human and dogs, in addition to inter-species an intra species difference has also been reported in dogs [33]. Various factors could contribute to the individual variations within the species; these include age, body weight, lean-to-fat body ratio and genetics [34-36]. Although there is no data reporting the influence of genetic factors on the disposition of ketamine in dogs, its potential role cannot be excluded. In this study, we selected the ketamine dose based on the prior results reported by Bergadano et al. [20]. We used similar loading dose of $0.5 \mathrm{mg} / \mathrm{kg}$, but increased the CRI to 30 and $50 \mu \mathrm{g} / \mathrm{kg} / \mathrm{min}$, doses 3 and 5 times higher than that used by Bergadano. Both the doses maintained serum concentration above the level required to raise the mechanical nociceptive thresholds up to $120 \mathrm{~min}$. Our study showed that the mechanical nociceptive threshold in dogs can be raised through ketamine infusion. In order to maintain this plasma concentration and have an antinociceptive effect over $120 \mathrm{~min}$, higher infusions rates than previously employed by Bergadano et al. in dogs (20) are deemed necessary. A time of $120 \mathrm{~min}$ was selected in our study to simulate a multimodal analgesic approach that could provide pre-intra and post-operative antinociception for a potential surgery of $45 \mathrm{~min}$. This period covers the time before, during and after surgery up to recovery. Thus, results of this study confirmed the need for higher infusion rates of ketamine in dogs than that previously employed by Bergadano in dogs [20].

In the present study, the concentration of ketamine was higher during first $10-20 \mathrm{~min}$ of adminsitration, and declined gradually thereafter. The initial hike and maintenance of the higher serum concentrations were likely contributed by the loading dose. Since ketamine is a high clearance drug, it requires continuous infusion for at least five half lives, which is approximately $10 \mathrm{~h}$ to maintain steady state [37]. Ketamine also increases sympathetic nervous system activity, resulting in increased cardiovascular functions and hepatic blood flow [38, 39]. Thus, the elevated heart rates in the present study are likely a reflection of sympathetic stimulation by ketamine. 
Nociceptive mechanical thresholds increased significantly compared to baseline after administration of the K30, KL30 and K50 groups and remained elevated throughout the 120-minutes of infusion. The thresholds returned to baseline at $140 \mathrm{~min}$, that is, within $20 \mathrm{~min}$ after the end of infusion. Mechanical thresholds have been used in previous studies in animals [14, 26-28, 40-45] for the objective quantification of pain and to evaluate the analgesic efficacy of drugs. The analgesic effect of the test drug reported by these studies was either increase in the mechanical thresholds at the site of test compared to baseline $[26,28]$ or concurrent rise in the mechanical thresholds equal to that produced by positive control analgesic or dose used to compare with $[40,45]$ or equal rise in mechanical thresholds at the site of surgery by the same drug compared for two routes of administration [40, 44]. Kukanich et al. (2005) and Kaka et al. (2015) reported increase in mechanical thresholds after administration of intravenous morphine at $1 \mathrm{mg} / \mathrm{kg}[26,28]$. The increase in mechanical thresholds compared to baseline in these studies was suggestive of analgesic action of morphine. In the present study mechanical thresholds increased significantly compared to baseline in K30, KL30 and K50 treatments throughout the infusion period of $120 \mathrm{~min}$ and returned to baseline within $20 \mathrm{~min}$ after the end of infusion. The rise in mechanical thresholds suggests the antinociceptive actions of K30, KL30 and K50 throughout the duration of infusion. The modified algometer and technique used in this study have been validated previously in our lab [28]. In this study, conscious vocalization may not be a good indicator of nociceptive threshold as it occurred only in 2 of subjects, and therefore we depended on algometer readings, even though vocalization has been accepted as part of the pain study protocol in human beings.

Mechanical pressure for quantification of surgical pain or hyperalgesia is termed as "algometry". Algometry has been used to identify abnormal pain thresholds and to monitor response to analgesic treatment in animals and humans [46-49]. Algometry has also been used to evaluate the analgesic effects of drugs in dogs [26, 27, 40]. Rate of force of application plays a crucial part on the reliability of this method. Application of force at a faster rate may provoke a low false threshold reading [50]. In a study of reliability and validity of algometer Kinser et al. (2009) concluded that this is highly reliable and valid method [51]. The authors suggested that with some practice, an individual becomes reliable in applying force with an algometer. In this study researcher who operated the algometer has sufficient practice in applying the rate of force of application during preliminary experiments, which have been demonstrated as consistent results in saline treatment during validation of the method [28]. Similarly, in this study no significant difference in mechanical thresholds between control and $140 \mathrm{~min}$ indicates the reliability of results. Thus, the results of the above studies suggest that algometry is reliable and valid technique for the quantification of mechanical nociceptive thresholds. It should be noted that despite an open label approach of the current study, potential operator bias was minimized by blinding the operator of the algometer to the threshold values. Only another nearby observer who was not operating the algometer was entrusted to record the readings displayed on the LCD screen. It should be noted that the operator of the algometer, cannot see the values projected on the LCD screen. We are aware that open label studies have the limitation that results could be refined and biased [51], however, we tried to minimise the bias by blinding to the treatment the investigator who evaluated sedation and side effects of the infusions, and the investigator operating the algometer to the values recorded.

Ketamine has been reported to increase body temperature in dogs [23]. Effects of body temperature on mechanical thresholds in dogs have not been reported. In this study body temperatures increased significantly from baseline throughout study, however, this increase was within the normal range. The increase in mechanical thresholds throughout infusion and decrease in the mechanical thresholds after the end of infusion, at which time the temperature was still higher than baseline suggests that increase in temperatures did not affect the mechanical thresholds.

Ketamine is well known for its psychomimetic effects in dogs; these effects range from hypersalivation to excitability and delirium. The dose regimens used in this study did produce such side effects; however they were harmless and ceased within $20 \mathrm{~min}$ of ending the infusions. Furthermore, side effects were less intense and occurred less frequently in K30 and KL30 compared to K50. The sedation score recorded in this study was as low as 0 in $\mathrm{K} 30$ and KL30, and as high as 3 in K50, which is mild and comparable to the scores reported by Bergadano et al. [20].

Commonly used potent analgesics reduce the minimum alveolar concentration (MAC) of inhalant anaesthetics in dogs and humans $[52,53]$; the reduction in MAC of inhalant anaesthetic has been suggested either due to analgesic or sedative effects of the drug. Hence, if a drug decreases the MAC, it should be tested for its analgesic effects in awake patients [54]. The dosage of lidocaine selected in this study was based on MAC studies in dogs under anaesthesia [25] and studies in conscious dogs [55]. In the study on conscious dogs, lidocaine CRI of $100 \mu \mathrm{g} / \mathrm{kg} / \mathrm{min}$ up to four hours did not produce any side effect [55]. Therefore, lidocaine at $2 \mathrm{mg} / \mathrm{kg}$ loading dose and CRI $100 \mu \mathrm{g} / \mathrm{kg} / \mathrm{min}$ was combined to ketamine in this study. This combination of lidocaine and ketamine in present study was tested in preliminary study on two dogs before actual experiments. The major benefit 
of combining lidocaine and ketamine is to decrease the drug related side effects [56], decrease opioid requirement [57] intensity of pain in postoperative period due to central sensitization during surgical intervention [21]. The addition of lidocaine at $2 \mathrm{mg} / \mathrm{kg}$ loading dose and CRI of $100 \mu \mathrm{g} / \mathrm{kg} / \mathrm{min}$ to ketamine infusion in this study resulted in higher mean nociceptive threshold values only at carpal pad and metacarpal footpad. Whereas, no difference in the serum concentration between $\mathrm{K} 30$ and KL 30 as well as KL 30 and K50 was observed due to addition of lidocaine to ketamine. The inherent high individual variability in these parameters would require large sample size to demonstrate statistical difference, which was not feasible in this study.

In this study, overall nociceptive thresholds were relatively higher in K50 than K30. Suggesting that K50 provided slightly more analgesia than $\mathrm{K} 30$. On the other hand, there was no such difference between KL30 and K50. Thus, K 50 and KL30 demonstrated more or less similar effect on nociceptive thresholds than K30. Nevertheless, all the three regimens significantly raised nociceptive thresholds from baseline thresholds, suggesting significant analgesic effects demonstrated by the three regimens used. Further studies are required to investigate the analgesic effects of these three doses in dogs undergoing surgical procedures.

\section{Conclusions}

All the three treatment regimes in this study maintained serum concentrations of ketamine above $200 \mathrm{ng} / \mathrm{mL}$ and raised mechanical nociceptive thresholds at most body points during the $120 \mathrm{~min}$ of infusions. A linear correlation between the mechanical thresholds and serum concentrations of ketamine was found. Results from this study suggested that the minimum concentration of ketamine to produce analgesia in dogs is between 100 and $200 \mathrm{ng} / \mathrm{mL}$. All the three treatments provided antinociceptive effects throughout the infusions. In this setting the addition of lidocaine to ketamine increased mechanical thresholds without any further side effect. Clinical studies are encouraged to evaluate the analgesic effects of ketamine CRI and combination of lidocaine and ketamine at these dose regimens.

\section{Acknowledgments}

The authors are very grateful to the Faculty of Veterinary Medicine, Universiti Putra, Malaysia and Sindh Agriculture University Tandojam, Pakistan.

\section{Funding}

No funding resources for this study.

\section{Availability of data and materials}

Data and material supporting the results of this study are present in the main manuscript.

\section{Authors' contributions}

UK and $C H C$ contributed to original idea and design of the study. AAA, AK UK and $A A B$ conducted the experiments and collected the data. UK, BS and SF performed HPLC analysis. UK, ME and YMG performed statistical analysis. All authors were involved in the manuscript preparation and approved the final manuscript.

Competing interests

The authors declare that they have no competing interests.

\section{Consent for publication}

Not applicable.

\section{Ethics approval and consent to participate}

The study was approved by the Institutional Animal Care and Utility Committee of Universiti Putra Malaysia (Reference Number UPM/IACUC/AUPR023/2013).

\section{Author details}

${ }^{1}$ Department of Veterinary Clinical Studies, Faculty of Veterinary Medicine, Universiti Putra Malaysia, 43400 Serdang, Selangor, Malaysia. ${ }^{2}$ Department of Surgery and Obstetrics, Faculty of Animal Husbandry \& Veterinary Sciences, Sindh Agriculture University Tandojam, Sindh 70060, Pakistan. ${ }^{3}$ Material Synthesis and characterization laboratory, Institute of Advanced technology, Universiti Putra Malaysia, 43400 Serdang, Selangor, Malaysia. ${ }^{4}$ Department of Veterinary Preclinical Sciences, Faculty of Veterinary Medicine, Universiti Putra Malaysia, 43400 Serdang, Selangor, Malaysia. ${ }^{5}$ Institutes of Tropical Agriculture, Universiti Putra Malaysia, 43400 Serdang, Selangor, Malaysia. ${ }^{6}$ Laboratory of Vaccines and Immunotherapeutics, Institute of Bioscience, Universiti Putra Malaysia, 43400 Serdang, Selangor, Malaysia. ${ }^{7}$ Department of Human Anatomy, Faculty of Medicine and Health Science, Universiti Putra Malaysia, 43400 Serdang, Selangor, Malaysia. ${ }^{8}$ Department of Animal Sciences, Faculty of Agriculture, Universiti Putra Malaysia, 43400 Serdang, Selangor, Malaysia. ${ }^{9}$ Faculty of Animal Husbandry \& Veterinary Sciences, Sindh Agriculture University Tandojam, Sindh 70060, Pakistan.

Received: 28 November 2015 Accepted: 30 August 2016

Published online: 09 September 2016

\section{References}

1. Babos MB, Grady B, Wisnoff W, McGhee C. Pathophysiology of pain. Dis Mon. 2013;59(10):330-58

2. Schaible HG, Ebersberger A, Natura G. Update on peripheral mechanisms of pain: beyond prostaglandins and cytokines. Arthritis Res Ther. 2011;13(2): 210.

3. Tao YX. Dorsal horn alpha-amino-3-hydroxy-5-methyl-4-isoxazolepropionic acid receptor trafficking in inflammatory pain. Anesthesiology. 2010;112(5): 1259-65.

4. Zhuo M. Plasticity of NMDA receptor NR2B subunit in memory and chronic pain. Mol Brain. 2009;2(4):1756-6606.

5. Wilder-Smith $\mathrm{OH}$, Arendt-Nielsen L. Postoperative hyperalgesia: its clinical importance and relevance. Anesthesiology. 2006;104(3):601-7.

6. De Kock MF, Lavand'homme PM. The clinical role of NMDA receptor antagonists for the treatment of postoperative pain. Best Pract Res Clin Anaesthesiol. 2007:21(1):85-98.

7. Stubhaug A, Breivik H, Eide P, Kreunen M, Foss A. Mapping of punctuate hyperalgesia around a surgical incision demonstrates that ketamine is a powerful suppressor of central sensitization to pain following surgery. Acta Anaesthesiol Scand. 1997:41(9):1124-32.

8. Zakine J, Samarcq D, Lorne E, Moubarak M, Montravers P, Beloucif S, et al. Postoperative ketamine administration decreases morphine consumption in major abdominal surgery: a prospective, randomized, double-blind, controlled study. Anesth Analg. 2008;106(6):1856-61.

9. Aida S, Yamakura T, Baba H, Taga K, Fukuda S, Shimoji K. Preemptive analgesia by intravenous low-dose ketamine and epidural morphine in gastrectomy: a randomized double-blind study. Anesthesiology. 2000;92(6):1624-30.

10. Fu ES, Miguel R, Scharf JE. Preemptive ketamine decreases postoperative narcotic requirements in patients undergoing abdominal surgery. Anesth Analg. 1997;84(5):1086-90.

11. Domino EF, Zsigmond EK, Domino LE, Domino KE, Kothary SP, Dominof SE Plasma levels of ketamine and two of its metabolites in surgical patients 
using a gas chromatographic mass fragmentographic assay. Anesth Analg. 1982;61(2):87-92.

12. Javery KB, Ussery TW, Steger HG, Colclough GW. Comparison of morphine and morphine with ketamine for postoperative analgesia. Can J Anaesth. 1996;43(3):212-5.

13. Sarrau S, Jourdan J, Dupuis-Soyris F, Verwaerde P. Effects of postoperative ketamine infusion on pain control and feeding behaviour in bitches undergoing mastectomy. J Small Anim Pract. 2007;48(12):670-6.

14. Slingsby LS, Waterman-Pearson AE. The post-operative analgesic effects of ketamine after canine ovariohysterectomy - a comparison between pre-or post-operative administration. Res Vet Sci. 2000;69(2):147-52.

15. Wagner AE, Walton JA, Hellyer PW, Gaynor JS, Mama KR. Use of low doses of ketamine administered by constant rate infusion as an adjunct for postoperative analgesia in dogs. J Am Vet Med Assoc. 2002;221(1):72-5.

16. Richebe P, Rivat C, Rivalan B, Maurette P, Simonnet G. Low doses ketamine: antihyperalgesic drug, non-analgesic. Ann Fr Anesth Reanim. 2005;24(11-12): 1349-59.

17. Schmid RL, Sandler AN, Katz J. Use and efficacy of low-dose ketamine in the management of acute postoperative pain: a review of current techniques and outcomes. Pain. 1999;82(2):111-25.

18. Hansen BD. Assessment of pain in dogs: veterinary clinical studies. Ilar Journal. 2003;44(3):197-205.

19. Holton LL, Scott EM, Nolan AM, Reid J, Welsh E, Flaherty D. Comparison of three methods used for assessment of pain in dogs. J Am Vet Med Assoc. 1998;212(1):61-6.

20. Bergadano A, Andersen OK, Arendt-Nielsen L, Theurillat $R$, Thormann W, Spadavecchia C. Plasma levels of a low-dose constant-rate-infusion of ketamine and its effect on single and repeated nociceptive stimuli in conscious dogs. Vet J. 2009;182(2):252-60.

21. Muir WW, Woolf CJ. Mechanisms of pain and their therapeutic implications. J Am Vet Med Assoc. 2001;219(10):1346-56.

22. Matsubara LM, Oliva VN, Gabas DT, Oliveira GC, Cassetari ML. Effect of lidocaine on the minimum alveolar concentration of sevoflurane in dogs. Vet Anaesth Analg. 2009;36(5):407-13.

23. Solano AM, Pypendop BH, Boscan PL, Ilkiw JE. Effect of intravenous administration of ketamine on the minimum alveolar concentration of isoflurane in anesthetized dogs. Am J Vet Res. 2006;67(1):21-5.

24. Valverde A, Doherty TJ, Hernández J, Davies W. Effect of lidocaine on the minimum alveolar concentration of isoflurane in dogs. Vet Anaesth Analg. 2004;31(4):264-71.

25. Wilson J, Doherty TJ, Egger CM, Fidler A, Cox S, Rohrbach B. Effects of intravenous lidocaine, ketamine, and the combination on the minimum alveolar concentration of sevoflurane in dogs. Vet Anaesth Analg. 2008; 35(4):289-96.

26. KuKanich B, Lascelles BDX, Papich MG. Assessment of a von Frey device for evaluation of the antinociceptive effects of morphine and its application in pharmacodynamic modeling of morphine in dogs. Am J Vet Res. 2005;66(9): $1616-22$.

27. Lascelles BD, Cripps PJ, Jones A, Waterman AE. Post-operative central hypersensitivity and pain: the pre-emptive value of pethidine for ovariohysterectomy. Pain. 1997;73(3):461-71.

28. Kaka U, Chen HC, Goh YM, Abubakar AA, Fakurazi S, Ebrahimi M. Validation of a modified algometer to measure mechanical nociceptive thresholds in awake dogs. Biomed Res Int. 2015;2015:7. doi:10.1155/2015/375421.

29. Le Bars D, Gozariu M, Cadden SW. Animal models of nociception. Pharmacol Rev. 2001;53(4):597-652.

30. Faul F, Erdfelder E, Lang A-G, Buchner A. G* Power 3: A flexible statistical power analysis program for the social, behavioral, and biomedical sciences. Behav Res Methods. 2007;39(2):175-91.

31. Clements JA, Nimmo WS, Grant IS. Bioavailability, pharmacokinetics, and analgesic activity of ketamine in humans. J Pharm Sci. 1982;71(5):539-42.

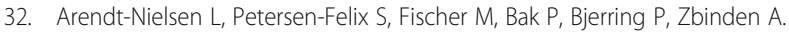
The effect of $\mathrm{N}$-methyl-D-aspartate antagonist (ketamine) on single and repeated nociceptive stimuli: a placebo-controlled experimental human study. Anesth Analg. 1995;81(1):63-8.

33. Pypendop BH, Ilkiw JE. Pharmacokinetics of ketamine and its metabolite, norketamine, after intravenous administration of a bolus of ketamine to isoflurane-anesthetized dogs. Am J Vet Res. 2005;66(12):2034-8.

34. Evans WE, Johnson JA. Pharmacogenomics: the inherited basis for interindividual differences in drug response. Annu Rev Genomics Hum Genet. 2001;2(1):9-39.
35. Palmer SN, Giesecke NM, Body SC, Shernan SK, Fox AA, Collard CD. Pharmacogenetics of anesthetic and analgesic agents. Anesthesiology. 2005: 102(3):663-71.

36. Spielberg SP. N-acetyltransferases: pharmacogenetics and clinical consequences of polymorphic drug metabolism. J Pharmacokinet Biopharm. 1996;24(5):509-19.

37. Wagner JG. A safe method for rapidly achieving plasma concentration plateaus. Clin Pharmacol Ther. 1974;16(4):691.

38. Adams HR, Parker JL, Mathew BP. The influence of ketamine on inotropic and chronotropic responsiveness of heart muscle. J Pharmacol Exp Ther. 1977;201(1):171-83.

39. Virtue R, Alanis J, Mori M, Lafargue R, Vogel J, Metcalf D. An anesthetic agent: 2-orthochlorophenyl, 2-methylamino cyclohexanone $\mathrm{HCl}(\mathrm{Cl}-581)$. Anesthesiology. 1967;28(5):823.

40. Buhari S, Hashim K, Yong Meng G, Mustapha NM, Gan SH. Subcutaneous Administration of Tramadol after Elective Surgery is as Effective as Intravenous Administration in Relieving Acute Pain and Inflammation in Dogs. Sci World J. 2012;2012:564939.

41. Hardie EM, Lascelles BDX, Meuten T, Davidson GS, Papich MG, Hansen BD. Evaluation of intermittent infusion of bupivacaine into surgical wounds of dogs postoperatively. Vet J. 2011;190(2):287-9.

42. Haussler KK, Erb HN. Mechanical nociceptive thresholds in the axial skeleton of horses. Equine Vet J. 2006;38(1):70-5.

43. Lascelles BDX, Cripps PJ, Jones A, Waterman-Pearson AE. Efficacy and kinetics of carprofen, administered preoperatively or postoperatively, for the prevention of pain in dogs undergoing ovariohysterectomy. Vet Surg. 1998;27(6):568-82.

44. Moak P, Hosgood G, Rowe E, Lemke K. Evaluation of intra-articular and subcutaneous administration of meloxicam for postoperative analgesia following stifle surgery in dogs. Vet Comp Orthop Traumatol. 2011;24(1):32.

45. Slingsby LS, Taylor PM, Murrell JC. A study to evaluate buprenorphine at $40 \mu \mathrm{kg}-1$ compared to $20 \mu \mathrm{g} \mathrm{kg}-1$ as a post-operative analgesic in the dog. Vet Anaesth Analg. 2011;38(6):584-93.

46. Chambers J, Waterman A, Livingston A. Further development of equipment to measure nociceptive thresholds in large animals. Vet Anaesth Analg. 1994;21(2):66-72.

47. Haussler K, Erb H. Pressure algometry for the detection of induced back pain in horses: a preliminary study. Equine Vet J. 2006;38(1):76-81.

48. Nussbaum EL, Downes L. Reliability of clinical pressure-pain algometric measurements obtained on consecutive days. Phys Ther. 1998;78(2):160-9.

49. Wylde V, Palmer S, Learmonth ID, Dieppe P. Somatosensory abnormalities in knee OA. Rheumatology. 2012;51(3):535-43.

50. Jensen K, Andersen HØ, Olesen J, Lindblom U. Pressure-pain threshold in human temporal region. Evaluation of a new pressure algometer. Pain. 1986;25(3):313-23.

51. Kinser AM, Sands WA, Stone MH. Reliability and validity of a pressure algometer. J Strength Cond Res. 2009;23(1):312-4.

52. Ko JC, Weil AB, Inoue T. Effects of carprofen and morphine on the minimum alveolar concentration of isoflurane in dogs. J Am Anim Hosp Assoc. 2009;45(1):19-23.

53. Machado CE, Dyson DH, Grant MM. Effects of oxymorphone and hydromorphone on the minimum alveolar concentration of isoflurane in dogs. Vet Anaesth Analg. 2006;33(1):70-7.

54. Boscan P, Monnet E, Mama K, Twedt DC, Congdon J, Eickhoff JC, et al. A dog model to study ovary, ovarian ligament and visceral pain. Vet Anaesth Analg. 2011;38(3):260-6.

55. MacDougall LM, Hethey JA, Livingston A, Clark C, Shmon CL, DukeNovakovski T. Antinociceptive, cardiopulmonary, and sedative effects of five intravenous infusion rates of lidocaine in conscious dogs. Vet Anaesth Analg. 2009;36(5):512-22.

56. Woolf CJ, Salter MW. Neuronal plasticity: increasing the gain in pain. Science. 2000:288(5472):1765-8

57. Kehlet H, Dahl JB. The value of "multimodal" or "balanced analgesia" in postoperative pain treatment. Anesth Analg. 1993;77(5):1048-56. 